\title{
THE TEXAS REPORT ON FORMAT PREFERENCES IN PUBLISHERS' RECORDINGS
}

\section{by Arthur J. Gionet and Gene H. Franks}

In the October, 1969, issue of the NALLD Journal, (pp. 68-71), Messrs. Glen M. Grosjean and Jesse O. Sawyer of the University of California at Berkeley have called upon laboratory directors to conduct their own surveys in their areas, such as the one they did in California, to determine the laboratory directors' preferences in publishers' recordings. In response to their request, the Department of Foreign Languages of North Texas State University, under the direction of Drs. Arthur J. Gionet and Gene H. Franks, undertook the task of gathering information from all the junior and senior colleges and universities, both private and public throughout the state of Texas, to complement the report from California.

On March 16, 1970, eighty-seven (87) one-page questionnaires were mailed and sixty-nine (69) were received by the May 4, 1970, deadline. Even though great care was exercised in the make-up of the questionnaire to avoid difficulties encountered in the California survey, all confusion was not eliminated, as was evident in the responses to certain items, such as Questions 5 and 10. (See below.) Yet, in spite of certain discrepencies in both the California and the Texas surveys, the results can furnish, at least, certain tendencies in language laboratory directors' preferences in tape recording formats. The findings of the Texas survey corroborate in most parts those found by Messrs. Grosjean and Sawyer in California.

Question 1: At what speed would you like the manufacturer's tape to be? 1
a) $41(61 \%)$ indicated $71 / 2$ or $33 / 4$
b) $2(3 \%)$ indicated $71 / 2$ only
c) $25(35 \%)$ indicated $33 / 4$ only
d) 0 indicated $17 / 8$
e) $1(1 \%)$ indicated no answer

Question 2: What size reel would you prefer?
a) $5(7 \%)$ indicated $10^{\prime \prime}$
b) $44(65 \%)$ indicated $7^{\prime \prime}$
c) $29(41 \%)$ indicated $5^{\prime \prime}$
d) $1(1 \%)$ indicated 3"
e) (other) 1 (1\%) indicated any size 


\section{Texas Report}

Question 3: Would you prefer open reels or cartridges?
a) $66(96 \%)$ preferred open reels
b) $3(4 \%)$ preferred cartridges

Question 4: Should the tapes be
a) full track (or one track only) $=43(63 \%)$
b) 2 tracks only $=28(40 \%)$
c) 4 tracks $=1(1 \%)$

'Even though the percentage adds up to $100 \%$ (69 answers) in Question 1, this is not true in every case. Many laboratory directors indicated several preferences in reel size, full-track or dual-track, etc., and at times, preferred not to answer some questions. One future laboratory director did not have a language laboratory but was interested in the finding of the Texas survey, which were promised to all participants.

Question 5: Do you use the manufacturer's tapes as they are?
a) $51(75 \%)$ said "yes"
b) $21(29 \%)$ said "no"
c) $3(4 \%)$ indicated "yes" and "no"

Question 6: Do you duplicate the tapes for your own use?
a) $53(76 \%)$ answered "yes"
b) $16(24 \%)$ answered"no"

Question 7: Do you adapt the tapes according to
a) $54(78 \%)$ material and time
b) 3 ( 4\%) material only
c) $5(7 \%)$ time only
d) 1 ( $1 \%)$ no change

Question 8: Do you use cartridges?
a) $12(16 \%)$ indicated "yes"
b) $55(81 \%)$ indicated "no"

Question 9: If yes, is it for

a) $2(3 \%)$ program use

b) $12(16 \%)$ student use

Note: Some of the directors' comments pertaining to the use of cartridges were quite unfavorable.

Question 10: A) What do you use for program source?

a) one track only (or $1 / 2$ track one side) $=43$ $(63 \%)$

b) two track

$$
\text { only }=18(25 \%)
$$

c) two track only $=7(10 \%)$

d) $7^{\prime \prime}$ reel $=46(67 \%)$

e) $5^{\prime \prime}$ reel $=22(31 \%)$

f) $10^{\prime \prime}$ reel $=4(5 \%)$ 
B) What do you use for student use?

a) one track only (or $1 / 2$ track one side) $=30(43 \%)$

b) two track only $=11(16 \%)$

c) two track only $=12(18 \%)$

d) $7^{\prime \prime}$ reel $=26(38 \%)$

e) $5^{\prime \prime}$ reel $=24(35 \%)$

f) $3^{\prime \prime}$ reel $=1(1 \%)$

Question 11: Do you think the manufacturer should furnish the exact text and content with time indicated in minutes and seconds for each group of items for each tape?

a) $60(87 \%)$ indicated "yes"

b) $1(1 \%)$.indicated " $\mathrm{no}$ "

c) $7(10 \%)$ indicated "indifferent"

Question 12: Should this information be included in the students' laboratory manual?
a) $37(53 \%)$ indicated "yes"
b) $12(18 \%)$ indicated "no"
c) $19(28 \%)$ indicated "indifferent"

Question 13: Should the book companies furnish the tapes for the textbooks?
a) $63(92 \%)$ indicated "yes"
b) $2(3 \%)$ indicated "no"
c) $2(3 \%)$ indicated "indifferent"

Question 14: Do you consider it fair that the school should buy the tapes necessary for the course?
a) $37(54 \%)$ indicated "yes"
b) $23(32 \%)$ indicated " $\mathrm{no}^{\circ}$
c) $6(9 \%)$ indicated "indifferent"

Note: Several laboratory directors stressed the fact that duplication at no cost to the university, as in the past, should be allowed, because the investment incurred in the purchase of tapes does not allow ample freedom in the adoption of new texts. Others felt that the purchase of tapes would guarantee a good set of tapes and would alleviate delay at crucial times of the year, such as late August and early September.

The evidence gathered in both the California and the Texas surveys shows that most language laboratory directors would like commercial tapes to be: a) on open reels (80\% Calif.; 95\% Texas); 
b) at a speed of $33 / 4$ i.p.s. ( $47 \%$ Calif.; $95 \%$ Texas); 1 c) on full track (26\% Calif.; ${ }^{2} 63 \%$ Texas); d) on 7 " reels (32\% Calif.: $65 \%$ Texas).

Since only $2 \%$ of the respondents from California and $4 \%$ from Texas preferred cartridges, it would seem that manufacturers' tapes on cartridges are not much in demand.

Messrs. Grosjean and Sawyer lamented the fact that $33 / 4$ i.p.s. tape speed is preferred by a majority of Californians over $71 / 2$ i.p.s. Texans also prefer $33 / 4$ i.p.s. over $71 / 2$ i.p.s., and only two language laboratory directors insisted on $71 / 2$ i.p.s. Evidently, most directors, unlike Messrs. Grosjean and Sawyer, do not see a qualitative need for the higher speed for good foreign-language tapes.

It is obvious that full track tapes are the choice of most language laboratory directors. Yet, there is evidence that many directors $(40 \%$ in Texas) are cost conscious and would just as soon have their commercial tapes on two-track tapes. Even though the use of quarter-track tapes is fairly common in California (p. 70), only one Texan preferred his tapes in this format.

The overwhelming majority of directors prefer the $7^{\prime \prime}$ reel, yet the manufacturers cannot neglect the demands of the minority for the 5" reel; $41 \%$ among Texans; $8 \%$ among Californians. ${ }^{3}$ It is suspected that $10^{\prime \prime}$ reels would also be acceptable if the equipment now in use in most schools (tape duplicators and recorders) could handle them.

Therefore, the findings of the California and Texas surveys should indicate to the manufacturers that, for these states, at least, language tapes ought to have the following format:

1. Open 7 " reel, 33/4 i.p.s., full track; 4 this format would satisfy approximately $60 \%$ of language laboratory directors;

2. Open $5^{\prime \prime}$ reel, 33/4 i.p.s., full track; 4 this format would satisfy approximately $30 \%$ of language laboratory directors. Other formats, such as reel size, $71 / 2$ i.p.s., four-track, cartridges, etc. could be offered by the companies through special orders.

\footnotetext{
IIncluded in this percentage is the following breakdown:

$35 \%$ insisted on $33 / 4$ i.p.s. and $60 \%$ indicated a speed of $71 / 2$ i.p.s. or $33 / 4$ i.p.s. Only $2 \%$ insisted on $71 / 2$ i.p.s.

2The low percentage reported in California is explained by the misunderstanding of the term "full track". See p. 71 of article.

3The California report is not clear on this point: " $32 \%$ prefer the 7 " reel and $8 \%$ the 5 " reel." (See p. 70 ) Should we assume that the remaining would like their tapes on other size reels?

IIt is estimated that half of those who prefer this format would be pleased to have at their disposal the choice of dual track instead of full track. In fact, Holt, Rinehart and Winston offers this option for the laboratory tapes that accompany the Laboratory Mamual for Harris and Leveque's Basic Conversational French, Fourth Edition.
} 
Questions 5, 6, and 7 were asked to determine as far as possible how commercial tapes are used in the larguage laboratory. Unfortunately, there was evident misunderstanding of Question 5. Fiftyone (51) directors answered that they used the manufacturers' tapes as they are, and yet, sixty-two (62) out of sixty-nine (69) respondents (see Question 7) replied that they adapted the tapes according to material and time. Only one director reported the use of manufacturers' tapes without any substantial change. There is no doubt, then, that tapes are duplicated and adapted to suit the needs of each foreign language department. It is very important for the manufacturers to note that the size of the reel, whether $7^{\prime \prime}$ or $5^{\prime \prime}$, the speed $33 / 4$ i.p.s. or $71 / 2$ i.p.s., full track or dual track are not as important as the fidelity of the tapes, the content and the time.

The replies received for Question 11 support the idea that "time" is of utmost importance pedagogically. Sixty (60) directors indicated that the exact text and time in minutes and seconds should be incorporated either in the students' laboratory manual (see Question 12) or in a separate table of contents. The main complaint of course coordinators continues to be the lack of detailed tables of contents for language tape materials. Countless hours are spent in timing and programming tapes, and much of this tedious work could be eliminated if book manufacturers would include this information in their texts and/or laboratory manuals.

The frequently-repeated statement that book companies are not in the magnetic tape business is certainly not true today when electronic gadgetry is essentially intermingled with their texts. Course coordinators and language laboratory directors are definitely seeking texts with tapes even with so-called "readers" and anthologies. The question of accompanying tapes with such texts becomes for the manufacturers a matter of great importance. The replies to Question 13 clearly indicate that book companies should furnish tapes to accom. pany their textbooks, at least on the elementary and intermediate levels, and probably on more advanced levels.

The fairly new policies of book manufacturers that universities and colleges must now purchase language tapes that accompany textbooks have aroused interesting discussions among laboratory directors and course coordinators. The adoption of a new text has taken on new dimensions. No longer is the cost of the text the only item to be considered, but the cost of the tapes, of duplication, of "cutting" or adapting must now enter the picture before a new text is adopted. Even though slightly more than $50 \%$ of Texas language laboratory directors feel that the book companies (see Question 14) are within their rights to ask the schools to purchase the tapes that accompany their chosen textbooks, many small schools, especially private colleges, 


\section{Texas Report}

feel that the new policies have placed undue restriction on their choice of classroom texts.

The solution to the problem is probably too complex to satisfy every laboratory director's needs, and a return to the duplication privileges would prove unsatisfactory as in the past with its broken and erased tapes. But it is clear from the additional comments made by Texas directors that purchased tapes should definitely not be priced any higher than the cost of good quality blank tape. Perhaps a partial solution can be found in a policy that would allow foreign language departments to exchange with the book companies new, specified-quality tapes for the needed recorded tapes. In this manner, tape quality control would be protected for both the company and the school. Another possible solution to the problem would be for the schools to use the services offered by NALLD' to sell their tapes that they no longer use. However, revised text and tape editions would greatly reduce resale possibilities of such tapes.

In conclusion, it must be said that both the California and Texas surveys have indicated possible paths for publishers to follow in the preparation of formats for language tapes. Even though the questionnaires were not faultless, they yielded enough valid information to guide the book companies in their format offerings. However, more surveys of other areas of the country are needed to confirm or reject the California and Texas findings. Better questionnaires, perhaps with a wider scope and under the guidance of NALLD, should be prepared, mailed and analyzed. It is only through fact-finding surveys, such as these conducted in California and Texas, that an understanding of laboratory directors' needs can be obtained and forwarded to book publishers.

ABOUT THE AUTHORS:

Dr. Gionet is the Language Laboratory Director, and Dr. Franks will be the Language Laboratory Director in the fall, 1970, at North Texas State University, Denton, Texas.

${ }^{1}$ NALLD Journal, Vol. IV, No. III, Mar., 1970, p. 7. 